\title{
$\mathrm{M}|\mathrm{R}| \mathrm{S}$ Internet Journal Nitride Semiconductor Research
}

\section{Low Temperature Nitridation Combined With High Temperature Buffer Annealing for High Quality GaN Grown by Plasma- Assisted MBE}

\author{
Gon Namkoong ${ }^{1}$, W. Alan Doolittle ${ }^{1}$, Sangbeom Kang ${ }^{1}$, Huang Sa ${ }^{1}$, April S. Brown ${ }^{1}$ and Stuart R. \\ Stock $^{2}$ \\ ${ }^{1}$ Georgia Institute of Technology, School of Electrical and Computer Engineering, \\ ${ }^{2}$ Georgia Institute of Technology, Materials Science and Engineering,
}

(Received Friday, September 22, 2000; accepted Monday, November 6, 2000)

\begin{abstract}
The effect of the initial nitridation of the sapphire substrate on the GaN crystal quality as a function of substrate temperature was studied. GaN layers were grown by plasma-assisted molecular beam epitaxy (MBE) on sapphire substrates nitridated at different substrate temperatures. A strong improvement in the GaN crystal quality was observed at $100^{\circ} \mathrm{C}$ nitridation temperature. Symmetric (0004) and asymmetric (10-5) full widths at half maximum (FWHM) of the X-ray rocking curves were 136 and 261 arcsec, respectively. This compares to an x-ray rocking curve full width at half maximum of 818 arcsec (0004) for conventional MBE buffer conditions. For our conventional buffer conditions, sapphire substrates were exposed to a $\mathrm{N}$ plasma at temperatures above $500{ }^{\circ} \mathrm{C}$ for $10 \mathrm{~min}$ and then 25 50nm buffers were deposited without annealing at high temperature. The low temperature nitridation also shows an enhancement of the lateral growth of the GaN, resulting in larger grain sizes. The largest grain size achieved was approximately $2.8 \mu \mathrm{m}$, while the average grain size was approximately $2.4 \mu \mathrm{m}$ at $100{ }^{\circ} \mathrm{C}$ nitridation temperature.
\end{abstract}

\section{Introduction}

Wide band-gap III-V nitrides are very promising for application to high-power, high-frequency, and hightemperature electronic devices due to their superior properties, such as the large breakdown field and high electron velocity. For improvements in these devices, it is necessary to produce $\mathrm{GaN}$ and related compounds with low defect density. In the absence of a suitable $\mathrm{GaN}$ substrate, $\mathrm{GaN}$ is grown on highly lattice-mismatched substrates, such as $\mathrm{Al}_{2} \mathrm{O}_{3}$, GaAs and $\mathrm{SiC}$. This leads to a high density of defects in the GaN that negatively impact optical and electrical properties. Therefore, a two-step growth consisting of pretreatment of the sapphire substrate prior to bulk growth was found to improve the quality of the GaN epitaxial layer [1]. Although these pretreatments do improve the crystal quality of the GaN, the nitridation effect on the crystal quality and lateral growth is not well understood.

In this letter, we demonstrate that the initial nitridation of the sapphire substrate plays a significant role in improving the crystal quality of $\mathrm{GaN}$ and proper nitridation enhances the grain size due to the promotion of the lateral growth. In particular, lower temperature nitridation, such as at $100{ }^{\circ} \mathrm{C}$ substrate temperature, can produce higher quality $\mathrm{GaN}$ and larger grain sizes.

\section{Experimental Details}

The samples were grown by molecular beam epitaxy (MBE) in a Riber 32 equipped with an EPI nitrogen source operated at $350 \mathrm{~W}$ and $0.5 \mathrm{sccm}$, and a conventional Knudsen cell for Ga. Basal c-plane sapphire substrates were degreased using organic solvents (trichloroethylene, acetone and methanol) in an ultrasonic cleaner and rinsed with DI water. The tantalumbacked sapphire substrates were indium bonded on a silicon wafer and then mounted on an EPI uniblock using custom-made spring plates. After being loaded into the introduction chamber, the sapphire substrates were outgassed at $700^{\circ} \mathrm{C}$ for one hour. To investigate the effect of the nitridation on the GaN structural quality and grain size, a series of experiments on the nitridation of the sapphire substrates was performed using a range of temperatures from 100 to $700{ }^{\circ} \mathrm{C}$. A $25 \mathrm{~nm}$ thick GaN buffer was deposited at a temperature of $500^{\circ} \mathrm{C}$. The temperature was raised to $800{ }^{\circ} \mathrm{C}$ to anneal the $\mathrm{GaN}$ buffer for 
10min. A $0.9 \mu \mathrm{m}$ thick $\mathrm{GaN}$ epitaxial layer was grown at $615^{\circ} \mathrm{C}$. Atomic force microscopy (AFM) measurements have been performed to determine the surface morphology of each of the layers after nitridation, buffer deposition, buffer annealing and bulk growth as a function of nitridation temperature. Only the nitridation and bulk results will be described here with more detailed results to follow in a subsequent publication. The crystal quality of the GaN films was measured by X-ray diffraction.

\section{Discussions and Results}

Nitridation of basal c-plane sapphire substrates was performed to investigate its effect on GaN structural quality and bulk grain size. The surface was exposed to $\mathrm{N}$ radicals as a function of temperature from $100^{\circ} \mathrm{C}$ to $700^{\circ} \mathrm{C}$. Figure 1, Figure 2 and Figure 3 show AFM images of the surfaces of the sapphire substrate after exposure for one hour to the nitrogen plasma at $100{ }^{\circ} \mathrm{C}, 200{ }^{\circ} \mathrm{C}$ and $700^{\circ} \mathrm{C}$, respectively. Substrate surface scratches that were introduced during the polishing process can be seen on the surfaces of all three samples. Figure 4 shows the surface roughness as a function of the nitridation substrate temperature. The root-mean-square surface roughness $\left(R_{\mathrm{RMS}}\right)$ of $2 \mu \mathrm{m} \times 2 \mu \mathrm{m}$ scans increases with decreasing nitridation temperature. As also observed by Kim et al. [2], this data suggests that higher temperature nitridation retains the smooth surface of the sapphire substrate.

The RHEED patterns were observed to confirm the formation of a crystalline $\mathrm{AlN}$ or $\mathrm{Al}_{\mathrm{x}} \mathrm{N}_{1-\mathrm{x}} \mathrm{O}$ layer. The samples nitridated at lower substrate temperatures such as at $100{ }^{\circ} \mathrm{C}$ and $200^{\circ} \mathrm{C}$ show streaky patterns after onehour nitridation, as shown in Figure 1 and 2 . The RHEED pattern for sample nitridated at $100^{\circ} \mathrm{C}$ was blurry compared with those nitridated at higher temperature. It may result from transmission of the electron beam through the rougher sapphire surface at the $100{ }^{\circ} \mathrm{C}$ nitridation. Taferner et al. showed that the nitridation of the sapphire substrate at low substrate temperature, e.g. $200{ }^{\circ} \mathrm{C}$, can also lead to the formation of $\mathrm{AlN}$ or $\mathrm{Al}_{\mathrm{X}} \mathrm{N}_{1-}$ ${ }_{x} \mathrm{O}$ layers [3]. AFM images after one-hour nitridation do not show any protrusions on the surfaces of the sapphire substrates, as shown in Figure 1, 2 and 3. These images suggest the formation of $\mathrm{Al}_{\mathrm{X}} \mathrm{N}_{1-\mathrm{x}} \mathrm{O}$, instead of $\mathrm{AlN}$ layers. Heinlein et al. showed that the sapphire surface exposed to $\mathrm{N}$ plasma radicals started to form $\mathrm{AlN}$ around $300 \mathrm{~min}$ at $400{ }^{\circ} \mathrm{C}$ substrate temperature [4], much longer than used in this study.

Thin GaN buffers $(25 \mathrm{~nm})$ were deposited at $500{ }^{\circ} \mathrm{C}$ substrate temperature on the sapphire substrates nitridated at different substrate temperatures. This was followed by an anneal for $10 \mathrm{~min}$ at $800{ }^{\circ} \mathrm{C}$ substrate temperature under nitrogen. The $0.9 \mu \mathrm{m} \mathrm{GaN}$ bulk was then grown under Ga stable growth conditions at $615^{\circ} \mathrm{C}$ substrate temperature, at a growth rate of $0.9 \mu \mathrm{m} / \mathrm{hr}$.

The GaN crystal quality was characterized by the $\omega$ scan of symmetric (0004) and asymmetric (10-5) reflecting planes with a Bede QC2a X-ray diffractometer. Figure 5 shows the $\mathrm{X}$-ray rocking curve results as a function of the nitridation temperature. It is clearly shown that the GaN crystal quality improves with decreasing nitridation temperature. It is well known that the values of symmetric FWHM do not give information on the threading dislocations that include edge components. Thus, an asymmetric X-ray measurement is required for further quantification of the structural quality. The GaN films grown on sapphire substrates at low nitridation temperatures lead to lower symmetric and asymmetric full widths at half maximum of the $\mathrm{x}$-ray rocking curves. The $0.9 \mu \mathrm{m} \mathrm{GaN}$ layers grown by $\mathrm{MBE}$ on the $100{ }^{\circ} \mathrm{C}$ nitridated sapphire substrate have x-ray rocking curve full width at half maximum (FWHM) of 136 arcsec (0004) and 261 arcsec (10-5). This compares to an $\mathrm{x}$-ray rocking curve full width at half maximum of 818 arcsec (0004) for conventional MBE buffer conditions. For the conventional buffer, sapphire substrates were exposed to a $\mathrm{N}$ plasma at temperatures above 500 ${ }^{\circ} \mathrm{C}$ for $10 \mathrm{~min}$ and then $25 \sim 50 \mathrm{~nm}$ buffers were deposited without annealing at high temperature.

In order to investigate the effects of the nitridation on the GaN lateral growth as a function of the nitridation temperature, GaN films grown on nitridated substrates at different substrate temperatures were characterized by atomic force microscopy (AFM). The results are shown in Figure 6, Figure 7 and Figure 8 . The $7.5 \mu \mathrm{m} \times 7.5 \mu \mathrm{m}$ AFM images show that there is the sudden change of the grain size from approximately $2 \mu \mathrm{m}$ to $2.4 \mu \mathrm{m}$ at $100{ }^{\circ} \mathrm{C}$ nitridation temperature. The largest grain size we can achieve was approximately $2.8 \mu \mathrm{m}$ at $100{ }^{\circ} \mathrm{C}$ nitridation temperature. However, the smoothest surface of the $\mathrm{GaN}$ was obtained at $200{ }^{\circ} \mathrm{C}$ nitridation temperature, as shown in Figure 4.

\section{Conclusion}

The initial nitridation of the sapphire substrate strongly affects the crystal quality of the GaN. Low temperature nitridation can produce high quality and smooth GaN. $\mathrm{GaN}$ layers grown by plasma assisted MBE after $100{ }^{\circ} \mathrm{C}$ temperature nitridation for one-hour shows a full width at half maximum of the $x$-ray rocking curves of 136 and 261 arcsec for symmetric (0004) and asymmetric (10-5) reflections, respectively. However, conventional growth condition produces GaN films of 818 arcsec for symmetric (0004) full width at half maximum of x-ray rocking curves. An enhanced lateral growth was also observed in GaN layers on lower temperature nitridated sapphire substrate. 


\section{ACKNOWLEDGMENTS}

The authors would like to thank Dr. L. A. Bottomley for technical advice. This work was supported by the Office of Naval Research under Grant No. N0001498-1-0209 monitored by Dr. Colin Wood.

\section{REFERENCES}

[1] H. Amano, N. Sawaki, I. Akasaki , Y. Toyoda , Appl. Phys. Lett. 48, 353-355 (1986).

[2] W Kim, M Yeadon, AE Botchkarev, SN Mohammad, JM Gibson, H Morkoc, J. Vac. Sci. Technol. B 15, 921-927 (1997).

[3] W. T. Taferner, A. Bensaoula, E. Kim, A. Bousetta, J. Cryst. Growth 164, 167 (1996).

[4] C. Heinlein, J. Grepstad, T. Berge, H. Riechert, Appl. Phys. Lett. 71, 341 (1997).

\section{FIGURES}
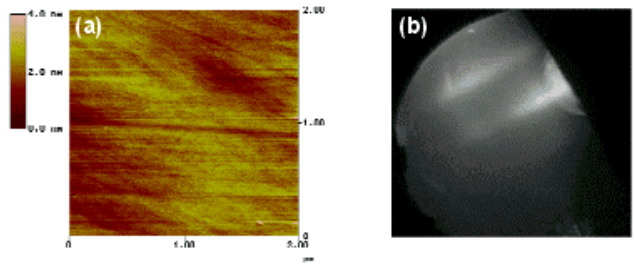

Figure 1. AFM image and RHEED pattern after one-hour nitridation at $100{ }^{\circ} \mathrm{C}[(\mathrm{a})$ and (b) $]$.
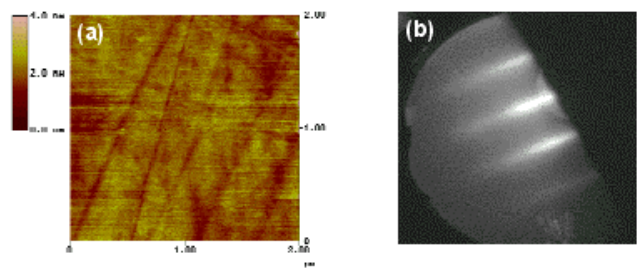

Figure 2. AFM image and RHEED pattern after one-hour nitridation at $200{ }^{\circ} \mathrm{C}[(\mathrm{a})$ and (b)].
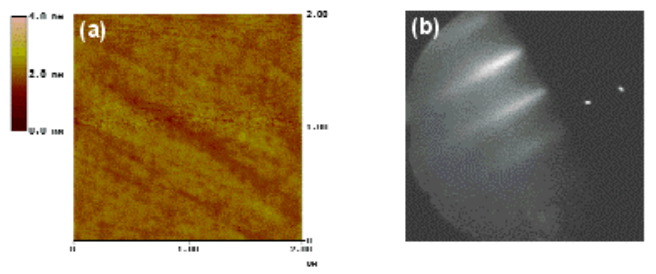

Figure 3. AFM image and RHEED pattern after one-hour nitridation at $700{ }^{\circ} \mathrm{C}[(\mathrm{a})$ and (b)].

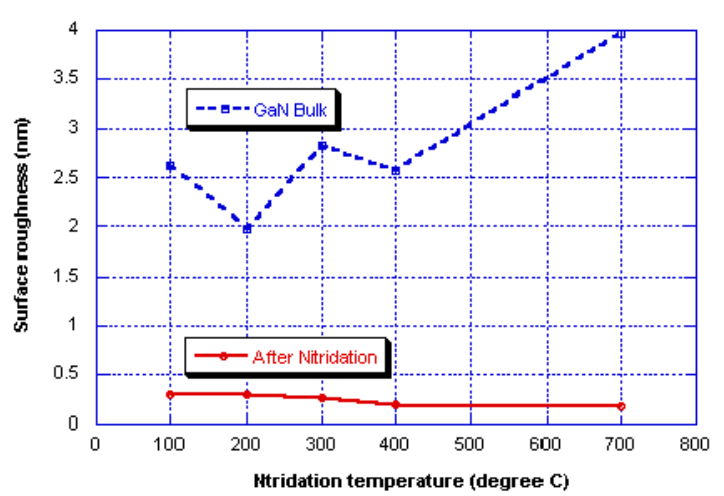

Figure 4. Surface roughness after one-hour nitridation and $\mathrm{GaN}$ bulk growth as a function of temperature.

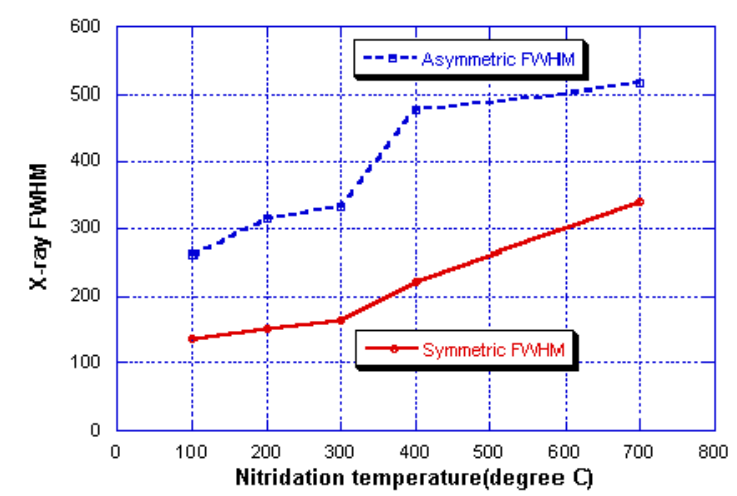

Figure 5. FWHM of the X-ray rocking curves for the symmetric and asymmetric reflections of $0.9 \mu \mathrm{m}-\mathrm{GaN}$ bulk.
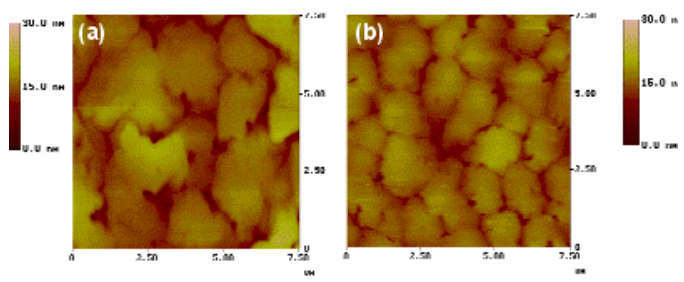

Figure 6. AFM images after the $0.9 \mu \mathrm{m}-\mathrm{GaN}$ bulk growth at (a) $100^{\circ} \mathrm{C}$, (b) $200^{\circ} \mathrm{C}$ for one-hour nitridation.
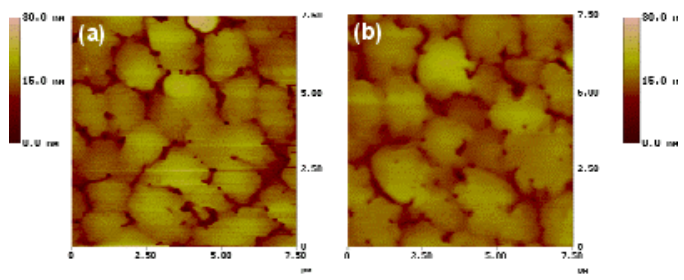

Figure 7. AFM images after the $0.9 \mu \mathrm{m}-\mathrm{GaN}$ bulk growth at (a) $300^{\circ} \mathrm{C}$, (b) $400^{\circ} \mathrm{C}$ for one-hour nitridation. 


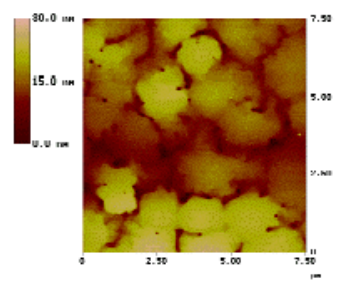

Figure 8 . AFM image after the $0.9 \mu \mathrm{m}-\mathrm{GaN}$ bulk growth at $700^{\circ} \mathrm{C}$ for one-hour nitridation. 